Patrizia De Marco • Maria Grazia Calevo • Anna Moroni

Lorenza Arata • Elisa Merello • Richard H. Finnell

Huiping Zhu • Luciano Andreussi • Armando Cama

Valeria Capra

\title{
Study of MTHFR and MS polymorphisms as risk factors for NTD in the Italian population
}

Received: January 17, 2002 / Accepted: March 8, 2002

\begin{abstract}
Homozygosity for the C677T mutation in the methylenetetrahydrofolate reductase $(M T H F R)$ gene is a risk factor for neural tube defects (NTDs) in many populations, including Italians. Another common mutation on the MTHFR gene, A1298C, has also been described as a risk mutation. Furthermore, several studies have suggested that a defective methionine synthase $(M S)$ enzyme could be a critical defect in folate-related NTDs. An A-to-G transition at bp 2756 on the $M S$ gene has also been reported. In this case-control study, we studied the frequencies of these two polymorphisms in 203 Italian probands with non-syndromic NTDs: 98 mothers, 67 fathers, and 210 control individuals. Although the A1298C polymorphism is common in the Italian population $(0.25)$, the allelic frequency was significantly higher among NTD cases and their parents. Heterozygous patients and mothers have an odds ratio (OR) of 1.98 and 2.11 , respectively. The risk associated with the $1298 \mathrm{CC}$ genotype was higher for cases $(\mathrm{OR}=3.67)$, for fathers $(\mathrm{OR}$ $=3.28)$, and, above all, for mothers (OR = 6.23). The prevalence of the $\mathrm{A} 2756 \mathrm{G}$ polymorphism of the $M S$ gene was determined (0.15). No increased prevalence of the mutated $\mathrm{G}$ allele was found in NTD families. This study shows that the MTHFR A1298C polymorphism is a genetic determinant for NTD risk in Italy. No association between the $M S$ A2756G and NTD susceptibility was found.
\end{abstract}

Key words Neural tube defects $\cdot M T H F R$ gene $\cdot M T H F R$ A1298C $\cdot M S$ gene $\cdot M S$ A2756G

P. De Marco - A. Moroni - L. Arata - E. Merello - L. Andreussi

A. Cama $\cdot$ V. Capra $(\square)$

Istituto G. Gaslini, Largo G. Gaslini, 516148 Genova, Italy

Tel. +39-010-5636712; Fax +39-010-3993159

e-mail: capraval@tin.it; valeriacapra@ospedale-gaslini.ge.it

M. Grazia Calevo

Servizio di Epidemiologia e Biostatistica, Istituto G. Gaslini,

Genova, Italy

R.H. Finnell $\cdot$ H. Zhu

Institute of Biosciences and Technology, Texas A\&M University

System Health Science Center, Houston, TX, USA

\section{Introduction}

Methylenetetrahydrofolate reductase $(M T H F R)$ plays a central role in folate-dependent homocysteine metabolism. Mutations in MTHFR have been reported as causes of hyperhomocysteinemia (Frosst et al. 1995; Jacques et al. 1996). The best-characterized MTHFR genetic polymorphism is a $677 \mathrm{C} \rightarrow \mathrm{T}$ transition that affects the predicted catalytic domain of the MTHFR protein. This mutation, resulting in decreased enzyme activity, is associated with mildly elevated plasma homocysteine levels and a redistribution of folates, namely, elevated red cell folate and lowered plasma folate (van der Put et al. 1995, 1996). Homozygosity for the 677T mutation predisposes individuals to the development of hyperhomocysteinemia, especially during times of folate insufficiency (Frosst et al. 1995; van der Put et al. 1998). Recently, a second common polymorphism in the MTHFR gene $(1298 \mathrm{~A} \rightarrow \mathrm{C})$ was discovered, leading to a glutamate-to-alanine substitution in the presumed regulatory domain of the protein. Individuals who are either heterozygous 1298AC or homozygous 1298CC showed decreased enzyme activity, although their plasma homocysteine levels were not altered significantly (van der Put et al. 1998; Weisberg et al. 1998).

Given its key role in folate metabolism, it has been suggested that MTHFR is an attractive candidate in the etiology of neural tube defects (NTDs) because periconceptional folic acid supplementation is known to reduce the occurrence and recurrence risk for women to give birth to an NTD child (MRC Vitamin Study Research Group 1991; Czeizel and Dudas 1992). Moreover, significantly elevated plasma homocysteine levels and reduced folate levels were found in mothers of NTD-affected children (Mills et al. 1995; Whitehead et al. 1995). Therefore, the two MTHFR polymorphisms $(677 \mathrm{C} \rightarrow \mathrm{T}$ and $1298 \mathrm{~A} \rightarrow \mathrm{C})$ have been widely investigated as genetic risk factors for NTDs. Although the MTHFR C677T mutation is considered a genetic risk factor for NTD by some (Kirke et al. 1993; Mills et al. 1995; van der Put et al. 1995, 1996, 1997a; Whitehead et al. 1995; Ou et al. 1996), there are studies that could not 
confirm this mutation as a major determinant for NTD (Papapetrou et al. 1996; Mornet et al. 1997; Speer et al. 1997; Boduroglu et al. 1998; Koch et al. 1998; Weitkamp et al. 1998; Shaw et al. 1999). The C677T mutation was studied in the Italian population, which has a relatively low prevalence of NTDs. In this study, an increased NTD risk was found for the T/T genotype (odds ratio $[\mathrm{OR}]=1.73$ ), and the corresponding attributable fraction was $10.8 \%$ (de Franchis et al. 1998).

To date, few studies have evaluated the frequency of the 1298A/C alleles in a normal population and in NTD families (van der Put et al. 1998; Weisberg et al. 1998; Friedman et al. 1999; Rady et al. 1999; Stegmann et al. 1999; Volcik et al. 2000; Dekou et al. 2001; Song et al. 2001). In two of these studies, combined heterozygosity of the two MTHFR variants appeared to be increased in NTD-affected children when compared with the controls (van der Put et al. 1998; Dekou et al. 2001). Therefore, additional investigations are needed to establish whether the A1298C polymorphism is an additional risk factor for folate-sensitive NTD.

Several studies have suggested that a defective methionine synthase $(M S)$ enzyme could be a critical defect in folate-related NTDs (Kirke et al. 1993; Scott and Weir 1994; Steegers-Theunissen et al. 1994; Mills et al. 1995). In fact, $M S$, a vitamin $\mathrm{B}_{12}$-dependent enzyme that catalyzes the remethylation of homocysteine to methionine, is essential for mantaining adequate intracellular methionine and tetrahydrofolate pools. An A-to-G transition at bp 2756, which converts an aspartic acid to glycine, has been investigated in NTD patients. No increased prevalence of the $2756 \mathrm{GG}$ and 2756AG genotypes was found in patients, and no correlation was observed between these two genotypes and homocysteine levels (Morrison et al. 1997; van der Put et al. 1997b; Shaw et al. 1999). Additional studies on MS variants are required to address the role of this variant on NTD risk.

In the present case-control study, we examined the genotype frequencies of the MTHFR A1298C polymorphism as well as the $M S$ A $2756 \mathrm{G}$ variant in the Italian population, and evaluated their impact on NTD individuals and their relatives. Our data show that the A1298C polymorphism is a contributing risk factor for NTDs.

\section{Subjects and methods}

Probands and controls

This study included 203 (100 male and 103 female) unrelated Italian probands with non-syndromic NTD recruited from the Spina Bifida Center of the Gaslini Hospital, Genoa; they were all alive with an age range between 1 month and 10 years, and all of them were the first occurrence in the nuclear family. Ninety-eight mothers and 67 fathers were also included in the investigation. All parents were young adults with a mean age of 35 years. NTD diagnoses were made according to the Tortori-Donati et al. (2000) classification. One hundred seventy-two cases were affected by open spinal dysraphisms (OSDs) (84.7\%) and
31 by closed spinal dysraphisms (CSDs) (15.3\%). Seventyfive percent of children with OSD presented with Chiari II malformation. Although the open lesions were limited to myelomeningocele $(N=172)$, the closed lesions included meningocele $(N=5)$, lipoma $(N=9)$, lipomyieloschisis $(N=12)$, dermal sinus $(N=3)$, and tight filum terminalis $(N=2)$. Two hundred ten unrelated healthy Italian volunteers (103 male and 107 female) were used as control group. They were young adults with an age range between 20 and 45 years; none of them suffered from NTDs or delivered an NTD-affected child. Informed consent was obtained from patients, parents, and control individuals.

\section{Genetic analysis}

DNA was isolated from peripheral leukocytes obtained in blood draws using standard procedures. The detection of the A1298C mutation was carried out by polymerase chain reaction/restriction fragment length polymorphism (PCR/ RFLP) screening, using two PCR primers to generate a 241bp fragment: a forward primer, 5'-ATGTGGGGGGAG GAGCTGAC-3', and the intronic reverse primer, 5'GTCTCCCAACTTACCCTTCTCCC- ${ }^{\prime}$. If the individual is homozygous wild type (1298AA), then the MboII RFLP results in two fragments, $204 \mathrm{bp}$ and $37 \mathrm{bp}$ in length. For the homozygous mutant MTHFR genotype (1298CC), only the 241-bp fragment is produced, and the heterozygous genotype generates all three fragments (van der Put and Blom 2000).

To screen for the $M S$ mutation (A2756G), an appropriate region of genomic DNA was amplified by using two specific primers (5'-GGTGTGTTCCCAGCTGTTA GATG-3' and 5'-GACACTGAAGACCTCTGATTTGA AC-3') and digested with HaeIII (van der Put et al. 1997b). A 2756AA genotype results in an uncut fragment of $265 \mathrm{bp}$, whereas a 2756AG genotype gives three fragments of 265 , 180 , and $85 \mathrm{bp}$. The homozygous $2756 \mathrm{GG}$ genotype produces two fragments of 180 and $85 \mathrm{bp}$. The digested PCR was separated on $3.5 \%-4 \%$ MetaPhor agarose (FMC BioProducts, Rockland, ME, USA) gel electrophoresis and stained by ethidium bromide. Direct sequencing of PCR fragments was used to confirm mutations. The sequencing reactions were manually performed using the Thermosequenase Cycle Sequencing Kit (Amersham, Buckinghamshire, UK), according to the manufacturer's instructions. The forward PCR primer for the MTHFR A1298C and the reverse PCR primer for C677T mutation analyses were used as sequencing primers.

\section{Statistical analysis}

Allele frequencies in the NTD patients, mothers, fathers, and controls were determined by counting alleles and calculating proportions. The Hardy-Weinberg equilibrium analysis was calculated using the data from the control group and was tested using chi-square statistics for goodness of fit (1 degree of freedom). The OR with an associated 95\% confidence interval (CI) was calculated to estimate the rela- 
tive risk of the different genotype combinations. MTHFR and $M S$ alleles frequencies were determined for the study and control groups, and were compared by $\chi^{2}$ analysis. Exact methods were considered preferable whenever expected numbers in any cell were less than five, and any results reported herein are based on exact methods. $P$ values $\leq 0.01$ were considered statistically significant, and all $P$ values were based on two-tailed tests.

The attributable fraction, representing the proportion of cases attributable to the presence of the mutation, was estimated using the equation proposed by Miettinen (1974).

The SPSS statistical software program was used for all analysis.

\section{Results}

Genotype distributions and allele frequencies

MTHFR and MS genotype distributions and allele frequencies for Italian NTD patients, parents, and controls are presented in Table 1 . We found a genotype frequency distribution for the MTHFR A1298C mutation that was as expected according to the Hardy-Weinberg equilibrium $\left(\chi^{2}=\right.$ $0.0325)$. A slight discordance was found for the genotype distribution of the $M S$ A2756G mutation $\left(\chi^{2}=4.06\right)$. The frequency of the C allele of the MTHFR A1298C mutation is 0.25 among control individuals. Thus, we have not revealed striking differences between the prevalence of the A1298C mutant allele among healthy Italian individuals and other populations that have already been studied (Weisberg et al. 1998; Rady et al. 1999). As shown in Table 1 , we found that the $1298 \mathrm{~A} / \mathrm{C}$ heterozygous and $1298 \mathrm{C} / \mathrm{C}$ homozygous genotypes were significantly more prevalent in NTD cases and parents than in controls. The A1298C fre- quencies were $0.39,0.44$, and 0.36 among patients, mothers, and fathers, respectively. The frequency of the $\mathrm{G}$ allele of the $M S$ A2756G polymorphism was 0.15 in the control population, which was in agreement with the incidence reported by other investigators (van der Put et al. 1997b). No increased prevalence of this mutated allele was found in NTD families, although a slightly higher frequency was present in patients and mothers (0.11) and in fathers (0.13).

No differences in the allele frequencies were found when we considered the type of defect. In fact, we found that the frequency of the $1298 \mathrm{C}$ allele between NTD children with open dysraphisms is 0.389 and with closed dysraphisms 0.370 . Similarly, no significantly increased prevalence of the 2756G allele was present in NTD cases affected by open (0.106) and closed (0.13) lesions.

Odds ratio and NTD risk

To evaluate the impact of the MTHFR A1298C variant on NTD risk in our sample, we calculated the OR and $95 \%$ CI associated with the $1298 \mathrm{~A} / \mathrm{C}$ and $1298 \mathrm{C} / \mathrm{C}$ genotypes (Table 2). The estimated OR for heterozygous NTD cases was 1.98 (95\% CI: $1.28-3.07 ; P \leq 0.001$ ), and increased to 3.67 (95\% CI: $1.67-8.18 ; P \leq 0.0003)$ for homozygous NTD cases. Furthermore, the NTD risk significantly increased if both homozygous and heterozygous NTD children were compared with control individuals $(\mathrm{OR}=2.21 ; 95 \%$ CI $1.46-$ 3.36; $P \leq 0.00008)$. More sensitive risk estimates resulted for the mothers: an increased risk of 2.11 (95\% CI: 1.19 $3.75 ; P \leq 0.006)$ and 6.23 (95\% CI: $2.58-15.35 ; P \leq 0.00001)$ was found for the prevalence of the 1298AC and 1298CC genotypes, respectively, and of 2.67 if both heterozygous and homozygous mothers were compared with controls. There was no increased risk for the heterozygous A1298C genotype of the fathers $(\mathrm{OR}=1.45 ; 95 \%$ CI: $0.77-2.74$;

Table 1. Genotype distribution and allele frequencies of $M T H F R$ A1298C and MS A2756G polymorphisms in Italian NTD families and controls

\begin{tabular}{|c|c|c|c|c|}
\hline & $\begin{array}{l}\text { NTD cases } \\
\%(N=203)\end{array}$ & $\begin{array}{l}\text { Mothers } \\
\%(N=98)\end{array}$ & $\begin{array}{l}\text { Fathers } \\
\%(N=67)\end{array}$ & $\begin{array}{l}\text { Controls } \\
\%(N=202)\end{array}$ \\
\hline $\mathrm{A} / \mathrm{A}$ & $36.9(N=75)$ & $32.7(N=32)$ & $43.3(N=29)$ & $56.4(N=114)$ \\
\hline $\mathrm{A} / \mathrm{C}$ & $48.8(N=99)$ & $45.9(N=45)$ & $41.8(N=28)$ & $37.6(N=76)$ \\
\hline $\mathrm{C} / \mathrm{C}$ & $14.3(N=29)$ & $21.4(N=21)$ & $14.9(N=10)$ & $5.9(N=12)$ \\
\hline $1298 \mathrm{~A}$ & 0.61 & 0.56 & 0.64 & 0.75 \\
\hline $1298 \mathrm{C}$ & 0.39 & 0.44 & 0.36 & 0.25 \\
\hline \multicolumn{5}{|c|}{$M S$ A2756G } \\
\hline & $\begin{array}{l}\text { NTD cases } \\
\%(N=174)\end{array}$ & $\begin{array}{l}\text { Mothers } \\
\%(N=75)\end{array}$ & $\begin{array}{l}\text { Fathers } \\
\%(N=48)\end{array}$ & $\begin{array}{l}\text { Controls } \\
\%(N=210)\end{array}$ \\
\hline $\mathrm{A} / \mathrm{A}$ & $79.3(N=138)$ & $82.7(N=62)$ & $77.1(N=37)$ & $70.5(N=148)$ \\
\hline $\mathrm{A} / \mathrm{G}$ & $19.5(N=34)$ & $12.0(N=9)$ & $18.8(N=9)$ & $29.0(N=61)$ \\
\hline $\mathrm{G} / \mathrm{G}$ & $1.1(N=2)$ & $5.3(N=4)$ & $4.2(N=2)$ & $0.5(N=1)$ \\
\hline $2756 \mathrm{~A}$ & 0.89 & 0.89 & 0.87 & 0.85 \\
\hline $2756 \mathrm{G}$ & 0.11 & 0.11 & 0.13 & 0.15 \\
\hline
\end{tabular}

NTD, Neural tube defect 
Table 2. Odds ratios with $95 \%$ confidence intervals of $M T H F R$ A1298C genotype in NTD cases, mothers and fathers

\begin{tabular}{lll}
\hline MTHFR A1298C & Odds ratio (95\% CI) & $P$ \\
\hline Controls-patients & $3.67(1.67-8.18)$ & \\
AA/CC & $1.98(1.28-3.07)$ & 0.0003 \\
AA/AC & $2.21(1.46-3.36)$ & 0.001 \\
AA/AC-CC & & 0.00008 \\
Controls-mothers & $6.23(2.58-15.35)$ & \\
AA/CC & $2.11(1.19-3.75)$ & 0.00001 \\
AA/AC & $2.67(1.57-4.59)$ & 0.006 \\
AA/AC-CC & & 0.0001 \\
Controls-fathers & $3.28(1.17-9.16)$ & 0.01 \\
AA/CC & $1.45(0.77-2.74)$ & $0.22^{*}$ \\
AA/AC & $1.70(0.94-3.08)$ & $0.06^{*}$ \\
AA/AC-CC &
\end{tabular}

NTD, Neural tube defect; CI, Confidence interval

* Not significant

$P=0.22$ not significant), but there is a trend toward an increased risk for fathers that have a homozygous mutant genotype $(\mathrm{OR}=3.28 ; 95 \%$ CI $1.17-9.16 ; P \leq 0.01)$. Thus, we estimate the attributable fraction of NTD cases due to the $M T H F R \mathrm{C} / \mathrm{C}$ genotype in Italy to be $7.8 \%$ and $10.4 \%$, depending on the comparison group used for the estimation of the risk (1298CC versus 1298AA, or 1298AC plus 1298CC, versus 1298AA).

Finally, the possible involvement of MS A2756G in the risk for NTD was investigated by analyzing the prevalence of the mutation in NTD patients and their parents. There was no significantly increased prevalence of $2756 \mathrm{AG}$ and 2756GG genotypes present in either the NTD patients or their parents when compared with the prevalence observed among the controls. Calculated OR indicates that neither the homozygous nor the heterozygous mutant genotype increased the NTD risk (data not shown), demonstrating that this polymorphism is not a risk factor for NTDs, but instead is most probably a benign polymorphism.

\section{Discussion}

In this study we investigated whether the MTHFR A1298C mutation, as reported for the C677T mutation, could have an impact on NTD in the Italian population. The 1298C allele frequency in Italy was determined to be 0.25 . Previous studies on the prevalence of this polymorphism revealed that there is wide heterogeneity in the prevalence of the A1298C polymorphism throughout the world, as reported for the C677T mutation. We found the frequency of the 1298C allele in Italy to be similar to that reported for the Canadian (0.25) (Weisberg et al. 1998) and Ashkenazi Jewish population (0.28) (Rady et al. 1999), demonstrating that this polymorphism is common in the Italian population, although its rate is lower than the C677T mutation. The results of the present study indicate an increased prevalence of heterozygosity and homozygosity for the MTHFR A1298C polymorphism among NTD patients and mothers. The level of the conferred risk was minor for heterozygous NTD cases $(\mathrm{OR}=1.98)$ and mothers $(\mathrm{OR}=2.11)$ and was higher for homozygous mutant genotypes of patients (OR $=3.67)$ and mothers $(\mathrm{OR}=6.23)$. The father's genotype appeared to be a significant risk factor if he has the homozygous $1298 \mathrm{CC}$ genotype $(\mathrm{OR}=3.28)$. The results of this study, which had a relatively large number of subjects, reproducible genotyping methods, and significantly increased OR, are unlikely to be due to selection bias. The allelic frequencies among our controls are consistent with those derived by Hardy-Weinberg equilibrium and those reported previously in other European populations, demonstrating the randomness of our control selection. However, since case-control studies of a single polymorphism can produce conflicting data, our results will be confirmed by a family-based transmission disequilibrium test. Furthemore, our results are biologically plausible because the A1298C mutation results in diminished enzyme activity. A significant decreasing effect on MTHFR activity has been observed in the homozygous $1298 \mathrm{CC}$ as well as in the heterozygous 1298AC state (van der Put et al. 1998). Therefore, there seems to be an interaction between the C677T mutation and the A1298C mutation, because heterozygosity for both mutations is associated with lower activity than heterozygosity alone for either mutation, resulting in increased homocysteine levels (van der Put et al. 1998). A limitation of the present study is that we did not have access to plasma samples for evaluation of the impact of the A1298C variant on folate and homocysteine levels in our cases and mothers. Since the A1298C mutation influences enzyme activity and homocysteine and folate concentrations to a lesser extent than does the C677T mutation, it may be expected that the A1298C mutation is a risk factor for NTD, but with a smaller relative risk. On the contrary, we found that the A1298C polymorphism is an important risk factor for the Italian population with a risk associated with the $1298 \mathrm{C} / \mathrm{C}$ genotype that is even higher than that reported for the homozygous mutant genotype of the C677T mutation (de Franchis et al. 1998). MTHFR nucleotide 1298 is located on the regulatory domain of the protein, where it may be involved in protein stabilization (Shan et al. 1999). We speculate that the effect of the A1298C variant results in the alteration of one-carbon metabolism within a cell rather than a simply generalized repression of MTHFR activity. This mutation could become of clinical importance, particulary under conditions of low intake of folate or high requirements of folate, such as occurs in pregnancy. The increased risk that we found in NTDaffected children and their mothers suggest that this mutation could be responsible for a proportion of NTD cases that is not explained by homozygosity for the C677T mutation.

Our finding of no association between the A2756G polymorphism in the $M S$ gene and the occurrence of the NTD phenotype is in agreement with the findings of other groups who did not report a direct or significant role for this polymorphism in the etiology of NTD (Morrison et al. 1997; van der Put et al. 1997b; Shaw et al. 1999; Johanning et al. 2000). Given the importance of $M S$ in homocysteine and folate metabolism, it is likely that during evolution, mutations of $M S$ were so deleterious that they were lethal to the fetus 
and were thus not propagated. The importance of this enzyme for early development has been recently demonstrated in mice by targeted disruption of the $M S$ gene. In fact, homozygous knock-out embryos survive through implantation but die soon thereafter (Swanson et al. 2001). Potential interaction of MTHFR and $M S$ variants may be of significance because $M S$ and MTHFR are both key enzymes in homocysteine and folate metabolism. Recently, it has been reported that associations between the 677T mutation in $M T H F R$ and the $M S$ A2756G polymorphism slightly increased NTD risk (Johanning et al. 2000). Further research should explore the comorbidity of MTHFR and MS polymorphisms in a large population.

Spinal dysraphisms are categorized as open (OSD) and closed (CSD) (Tortori-Donati et al. 2000). OSD is characterized by exposure of the nervous tissue and/or meninges to the environment through a congenital bony defect. Conversely, CSD is covered by skin (there is no exposed neural tissue), although cutaneous stigmata usually betray its presence. CSD is more heterogeneous than OSD and a large number of malformations belong to this group. In our study, we categorized our patients by type of dysraphism and we attempted to correlate it with MTHFR A1298C and MS A2756G genotype distribution. No statistically significant heterogeneity was found among NTD cases in the allelic frequency, demonstrating that neither variants could be associated to the type of defect. Moreover, the level of the defect was not always available and therefore could not be considered in the present study.

In conclusion, in this study we identified a second genetic risk factor for Italian NTD cases, the MTHFR A1298C mutation, which, like the C677T mutation, affects enzyme activity. From the point of view of general health care, the estimated OR of the A1298C mutation is of great importance because of the high prevalence of homozygous and heterozygous individuals in the general population. Homozygosity of NTD children for the A1298C mutation can at most explain $10.4 \%$ of the observed protective effect of folate. Since periconceptional folate supplementation reduces the risk for $70 \%$ of the population, other defective genes of folate, vitamin $\mathrm{B}_{12}$, or homocysteine metabolism may be associated with NTD risk.

Acknowledgments The authors express their appreciation to Dr. L. Rivabella (Immunohaematology Center and Transfusional Service, SIMT, Gaslini Institute) for technical support. We thank the patients and their families, whose collaboration and understanding have made this work possible. This study was supported by Ricerca Finalizzata Ministero della Sanità, contract grant numbers ICS 070.2/RF 99.22.

\section{References}

Boduroglu K, Alikasifoglu M, Anar B, Tuncbilek E (1998) 677-CT mutation on the methylenetetrahydrofolate reductase gene is not a risk factor for neural tube defects in Turkey. Arch Dis Child 78:F235

Czeizel AE, Dudas I (1992) Prevention of the first occurrence of neural-tube defects by periconceptual vitamin supplementation. $\mathrm{N}$ Engl J Med 327:1832-1835

de Franchis R, Buoninconti A, Mandato C, Pepe A, Sperandeo MP, Del Gado R, Capra V, Salvaggio E, Andria G, Mastroiacovo P
(1998) The C677T mutation of the 5,10-methylenetetrahydrofolate reductase gene is a moderate risk factor for spina bifida in Italy. $\mathrm{J}$ Med Genet 35:1009-1013

Dekou V, Whincup P, Papacosta O, Ebrahim S, Lennon L, Ueland PM, Refsum H, Humphries SE, Gunadson V (2001) The effect of the C677T and A1298C polymorphisms in the methylenetetrahydrofolate reductase gene on homocysteine levels in elderly men and women from the British regional heart study. Atherosclerosis 154: 659-666

Friedman G, Goldschmidt N, Friedlander Y, Ben-Yehuda A, Selhub J, Babaey S, Mendel M, Kidron M, Bar-ONH (1999) A common mutation A1298C in human methylenetetrahydrofolate reductase gene: association with plasma total homocysteine and folate concentrations. J Nutr 129:1656-1661

Frosst P, Blom HJ, Milos R, Gayette P, Sheppard CA, Mattews RG, Boers GJ, den Heijer M, Kluijtmans LA, van den Heuvel LP, Rozen R (1995) A candidate genetic risk factor for vascular disease: a common mutation in methylenetetrahydrofolate reductase. Nat Genet 10:111-113

Jacques PF, Bostom AG, Williams RR, Ellison RC, Eckfeldt JH, Rosenberg IH, Selhub J, Rozen R (1996) Relation between folate status, a common mutation in methylenetetrahydrofolate reductase, and plasma homocysteine concentrations. Circulation 93:7-9

Johanning GL, Tamura T, Johnston KE, Wenstrom KD (2000) Comorbidity of 5,10-methylenetetrahydrofolate reductase and methionine synthase gene polymorphisms and risk for neural tube defects. J Med Genet 37:949-951

Kirke PN, Molloy AM, Daly LE, Burke H, Weir DG, Scott J (1993) Maternal plasma folate and vitamin $\mathrm{B}_{12}$ are independent risk factors for neural tube defects. Q J Med 86:703-708

Koch MC, Stegmann K, Ziegler A, Schroter B, Ermert A (1998) Evaluation of the MTHFR C677T allele and the MTHFR gene locus in a German spina population. Eur J Pediatr 157:487-492

Miettinen OS (1974) Proportion of disease caused or prevented by a given exposure, trait or intervention. Am J Epidemiol 99:325-332

Mills JL, McPartlin JM, Kirke PN, Lee YJ, Conley MR, Weir DG, Scott JM (1995) Homocysteine metabolism in pregnancies complicated by neural-tube defects. Lancet 345:149-151

Mornet E, Muller F, Lenvoisè-Furet A, Delezoide A-L, Col J-Y, Simon-Bouy B, Serre J-L (1997) Screening of the C677T mutation on the methylenetetrahydrofolate reductase gene in French patients with neural tube defects. Hum Genet 100:512-514

Morrison K, Edwards YH, Lynch SA, Burn J, Hol F, Mariman E (1997) Methionine synthase and neural tube defects. J Med Genet 34:958

MRC Vitamin Study Research Group (1991) Prevention of neural tube defects: results of the Medical Research Council Vitamin Study. Lancet 338:131-137

Ou CY, Stevenson RE, Brown VK, Schwartz CE, Allen WP, Khoury MJ, Rozen R (1996) 5,10 methylenetetrahydrofolate reductase genetic polymorphism as a risk factor for neural tube defects. Am J Med Genet 63:610-614

Papapetrou C, Linch SA, Burn J, EdwardsYH (1996) Methylenetetrahydrofolate reductase and neural tube defects. Lancet 348: 58

Rady PL, Tyring SK, Hudnall SD, Vargas T, Kellner LH, Nitowsky H, Matalon RK (1999) Methylenetetrahydrofolate reductase (MTHFR): the incidence of mutations C677T and A1298C in the Ashkenazi Jewish population. Am J Med Genet 86:380-384

Scott JM, Weir DG (1994) Folate/vitamin B ${ }_{12}$ inter-relationship. Essays Biochem 28:63-72

Shan X, Wang L, Hoffmaster R, Kruger WD (1999) Functional characterization of human methylenetetrahydrofolate reductase in Saccharomyces cerevisiae. J Biol Chem 274:32613-32618

Shaw GM, Todoroff K, Finnell RH, Lammer EJ, Leclerc D, Gravel RA, Rozen R (1999) Infant methionine synthase variants and risk for spina bifida. J Med Genet 36:86-87

Song C, Xing D, Tan W, Wei Q, Lin D (2001) Methylenetetrahydrofolate reductase polymorphisms increase risk of esophageal squamous cell carcinoma in a Chinese population. Cancer Res 61: 3272-3275

Speer MC, Worley G, Mackey JF, Melvin E, Oakes WJ, George TM, Group NC (1997) The thermolabile variant of methylenetetrahydrofolate reductase (MTHFR) is not a major risk factor for neural tube defect in American Caucasians. Neurogenetics 1:149-150 
Steegers-Theunissen RPM, Boers GHJ, Trijbels FJM, Finkelstein JD, Blom HJ, Thomas CMG, Borm GF, Wouters MGAJ, Eskes TKAB (1994) Maternal hyperhomocysteinemia: a risk factor for neuraltube defects? Metabolism 43:1475-1478

Stegmann K, Ziegler A, Ngo ETKM, Kohlschmidt N, Schroter B, Ermert A, Koch M (1999) Linkage disequilibrium of $M T H F R$ geneotypes $677 \mathrm{C} / \mathrm{T}-1298 \mathrm{~A} / \mathrm{C}$ in the German population and association studies in probands with neural tube defects (NTD). Am J Med Genet 87:23-29

Swanson DA, Liu ML, Baker PJ, Garrett L, Stitzel M, Wu J, Harris M, Banerjee R, Shane B, Brody LC (2001) Targeted disruption of the methionine synthase gene in mice. Mol Cell Biol 21:1058-1065

Tortori-Donati P, Rossi A, Cama A (2000) Spinal dysraphism: a review of neuroradiological features with embryological correlations and proposal for a new classification. Neuroradiology 42:471-491

van der Put NMJ, Blom HJ (2000) Letter to editor. Am J Hum Genet 66:744-745

van der Put NMJ, Steegers-Theunissen RPM, Frosst P, Trijbels FJM, Eskes TKAB, van den Heuvel LP, Mariman ECM, den Heyer M, Rozen R, Blom HJ (1995) Mutated methylenetetrahydrofolate reductase as a risk factor for spina bifida. Lancet 346:1070-1071

van der Put NMJ, van den Heuvel LP, Steegers-Theunissen RPM, Trijbels FJM, Eskes TKAB, Mariman ECM, Blom HJ (1996) Decreased methylenetetrahydrofolate reductase activity due to the C-T mutation in families with spina bifida offspring. J Mol Med 74:691694

van der Put NMJ, Eskes TKAB, Blom HJ (1997a) Is the common $677 \mathrm{C} \rightarrow \mathrm{T}$ mutation in the methylenetetrahydrofolate reductase gene a risk factor for neural tube defects? A meta-analysis. Q J Med 90:505-510

van der Put NMJ, van der Molen EF, Kluitjtmans LAJ, Heil SG, Trijbels FJM, Eskes TKAB, van Oppenraaij-Emmerzaal D, Banerjee R, Blom HJ (1997b) Sequence analysis of the coding region of human methionine synthase: relevance to hyperhomocysteinaemia in neural-tube defects and vascular disease. Q J Med 90:511-517

van der Put NMJ, Gabreels F, Stevens EMB, Smeitink JAM, Trijbels FJM, Eskes TKAB, van den Heuvel LP, Blom HJ (1998) A second common mutation in the methylenetetrahydrofolate reductase gene: an additional risk factor for neural-tube defects? Am J Hum Genet 62:1044-1051

Volcik KA, Blanton SH, Tyerman GH, Jong ST, Rott EJ, Page TZ, Romaine NK, Northrup H (2000) Methylenetetrahydrofolate reductase and spina bifida: evaluation of level of defect and maternal genotypic risk in Hispanics. Am J Med Genet 95:21-27

Weisberg I, Tran P, Christensen B, Sibani S, Rozen R (1998) A second genetic polymorphism in methylenetetrahydrofolate reductase $(M T H F R)$ associated with decreased enzyme activity. Mol Genet Metab 64:169-172

Weitkamp LR, Tackels DC, Hunter AGW, Holmes LB, Schartz CE (1998) Heterozygote advantage of the MTHFR gene in patients with neural tube defect and their relatives. Lancet 351:1554-1555

Whitehead AS, Gallagher P, Mills JL, Kirke PN, Burke H, Molloy AM, Weir DG, Shields DC, Scott JM (1995) A genetic defect in 5,10 methylenetetrahydrofolate reductase in neural tube defects. Q J Med 88:763-766 